UCRL-ID-135763

\title{
Modeling of Steel Spheres Impacting Polyethylene
}

\author{
M. Gerassimenko, F. Serduke
}

July 16, 1999

U.S. Department of Energy

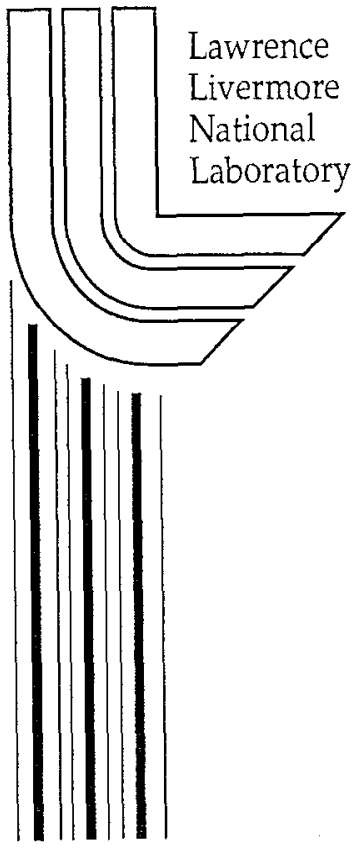




\section{DISCLAIMER}

This document was prepared as an account of work sponsored by an agency of the United States Government. Neither the United States Government nor the University of California nor any of their employees, makes any warranty, express or implied, or assumes any legal liability or responsibility for the accuracy, completeness, or usefulness of any information, apparatus, product, or process disclosed, or represents that its use would not infringe privately owned rights. Reference herein to any specific commercial product, process, or service by trade name, trademark, manufacturer, or otherwise, does not necessarily constitute or imply its endorsement, recommendation, or favoring by the United States Government or the University of California. The views and opinions of authors expressed herein do not necessarily state or reflect those of the United States Government or the University of California, and shall not be used for advertising or product endorsement purposes.

This report has been reproduced directly from the best available copy.

Available to DOE and DOE contractors from the Office of Scientific and Technical Information

P.O. Box 62, Oak Ridge, TN 37831

Prices available from (615) 576-8401, FTS 626-8401

Available to the public from the

National Technical Information Service

U.S. Department of Commerce

5285 Port Royal Rd.,

Springfield, VA 22161 


\title{
Modeling of Steel Spheres Impacting Polyethylene
}

\author{
Michel Gerassimenko and Franklin Serduke \\ $Q$ Division \\ Lawrence Livermore National Laboratory
}

\author{
March 1999
}

\section{Introduction}

The effect of shrapnel on target chamber components and experiments at large lasers such as the National Ignition Facility at LLNL and the Megajoule Laser at CESTA in France is an important issue in fielding targets and exposure samples. Modeling calculations are likely to be an important component of this effort. Some work in this area has been performed by French workers, who are collaborating with the LLNL on many issues relating to target chamber, experiment-component, and diagnostics survival.

Experiments have been performed at the Phébus laser in France to measure shrapnel produced by laser-driven targets; among these shots were experiments that accelerated spheres of a size characteristic of some of the more damaging shrapnel. These spheres were stopped in polyethylene witness plates. The penetration depth is characteristic of the velocity of the shrapnel. Experimental calibration of steel sphere penetration into polyethylene was performed at the CESTA facility. The penetration depth has been reported (ref. 1) and comparisons with modeling calculations have been made (ref. 2). There was interest in a comparison study of the modeling of these experiments to provide independent checks of the calculations. This work has been approved both by DOE headquarters and by the French Atomic Energy Commission (CEA); it is task number 993.2 of the 1999 ICF agreement between the DOE and the CEA. Daniel Gogny of the CEA who is on a long-term assignment to LLNL catalyzed this collaboration. This report contains the initial results of our modeling effort.

\section{Modeling}

Our first task was to reproduce, to the extent possible, Alain Geille's modeling (ref. 2) of the problem. To this end, we used the CALE 2-D axisymmetric code (ref. 3) run in an Eulerian mode. Zoning was uniform along the direction of the projectile velocity vector which is in the axial direction in the model. In the radial direction, uniform zoning was maintained out to $1 \mathrm{~mm}$ which was several projectile radii. Further out, radial zone size was increased by constant ratios of up to 1:1.05. A representative initial setup is 
presented in fig. 1 with zoning shown in the lower half. Zoning was chosen so that the projectile covers $\sim 20$ zones in the axial direction and a few more zones in the radial direction.

\section{First Calculations using CEA-style material models:}

Among the material models available to us, we selected those that matched, as closely as possible, the ones reported by the French modelers. The parameters of our model are listed in Table 1. The polyethylene elastic modulus and yield strength have been derived by French workers from experiments they conducted.

Our penetration results for steel spheres into polyethylene witness plates that used the French material properties are presented in Figures 2 through 5. The calculated penetration depth is compared to Geille's results (ref. 2) in Table 2. Our calculated penetrations exceed those of Geille in all cases but are not radically different. The shape of the projectile after it comes to rest is quite similar to that reported (ref. 2) except at the lowest incident velocity. At that velocity, our projectile shows hardly any of the flattening that is present in the French modeling. The recovered projectiles exhibited less deformation than the calculated shapes (refs. 2,4). Our computed penetration depths are compared with the French experimental data in fig. 6. It is evident that the computed depths exceed the experimental values.

\section{Second Calculations using modified material models:}

We then examined the effect of changes in the material parameters. The stainless-steel projectiles used in the experiments have not yet been characterized. We chose to model them with a Steinberg-Guinan constitutive model for stainless steel (ref. 5). This steel has the lowest yield strength of the few for which a Steinberg-Guinan model has been developed. We also changed the Gruneisen equation of state to that of 304 stainless steel. Furthermore, we decreased the spall strength of the polyethylene from $20 \mathrm{kbars}$ to 2 kbars, which we deem to be a more reasonable value. The material-model parameters for this set of calculations are presented in table 3 . These changes decreased the calculated penetration depths as well as the projectile deformation. By itself, the reduction on the polyethylene spall strength increases the calculated penetration depth by a few percent. Finally, we increased the yield strength of the polyethylene to $1.5 \mathrm{kbars}$. The results of these calculations are presented in figs. 7 through 10 , again at $10 \mu \mathrm{sec}$ which is long after the projectile stops. It is clear that the projectile deformation is reduced compared to our initial calculations. The calculated penetration depths for these calculations with improved material properties are compared to the experimental data in fig. 11. Agreement between the calculations and data is clearly improved and quite probably as good as can be expected in view of the scatter in the experimental data. 


\section{Summary:}

We have determined material parameters that produce good agreement between the modeling calculations and the experimental data. However, the projectile steel is as yet uncharacterized so it is not possible to draw firm conclusions about the significance of the agreement between the calculated and measured projectile shapes. It would also be interesting to know whether the deduced polyethylene yield strength is consistent with the 1.5 kbar value we have adopted.

It is expected that more extensive comparisons will be done during face-to-face meeting with our French counterparts under the aegis of the ICF agreement. A proposed time for this phase of the work would be just prior to or subsequent to the Bordeaux ICF meeting this fall. Final plans for the report to satisfy the ICF-Agreement tasking will be made then. Additional experimental work and modeling tasks will also be discussed at that time. 


\section{References:}

1. R. Courchinoux and A. Hereu, "Shrapnel generation and effects experiments at CESTA," presented at the LLNL/CEA meeting, September 22-26, 1997.

2. A. Geille, "Simulation of shrapnel experiments," presented at the LLNL/CEA meeting, September 22-26, 1997.

3. Robert Tipton, "The CALE Code", LLNL Internal Report. See also Robert Tipton, "Modeling Flux Compression Generators with a 2D ALE Code," LLNL Internal Report UCRL 99900, November 1988.

4. A. Geille, private communication.

5. D. J. Steinberg, S. G. Cochran, and M. W. Guinan, "A Constitutive Model for Metals Applicable at High Strain Rates," J. Appl. Phys., 51, 1498 (1980). Updates to this EOS are found in Daniel J. Steinberg "Equation of State and Strength Properties of Selected Materials" Lawrence Livermore National Laboratory Report UCRL-MA-106439 change 1, February 13, 1996 and references contained therein. 
Table 1

Material parameters for first calculations. Results are presented in figs. 2-6.

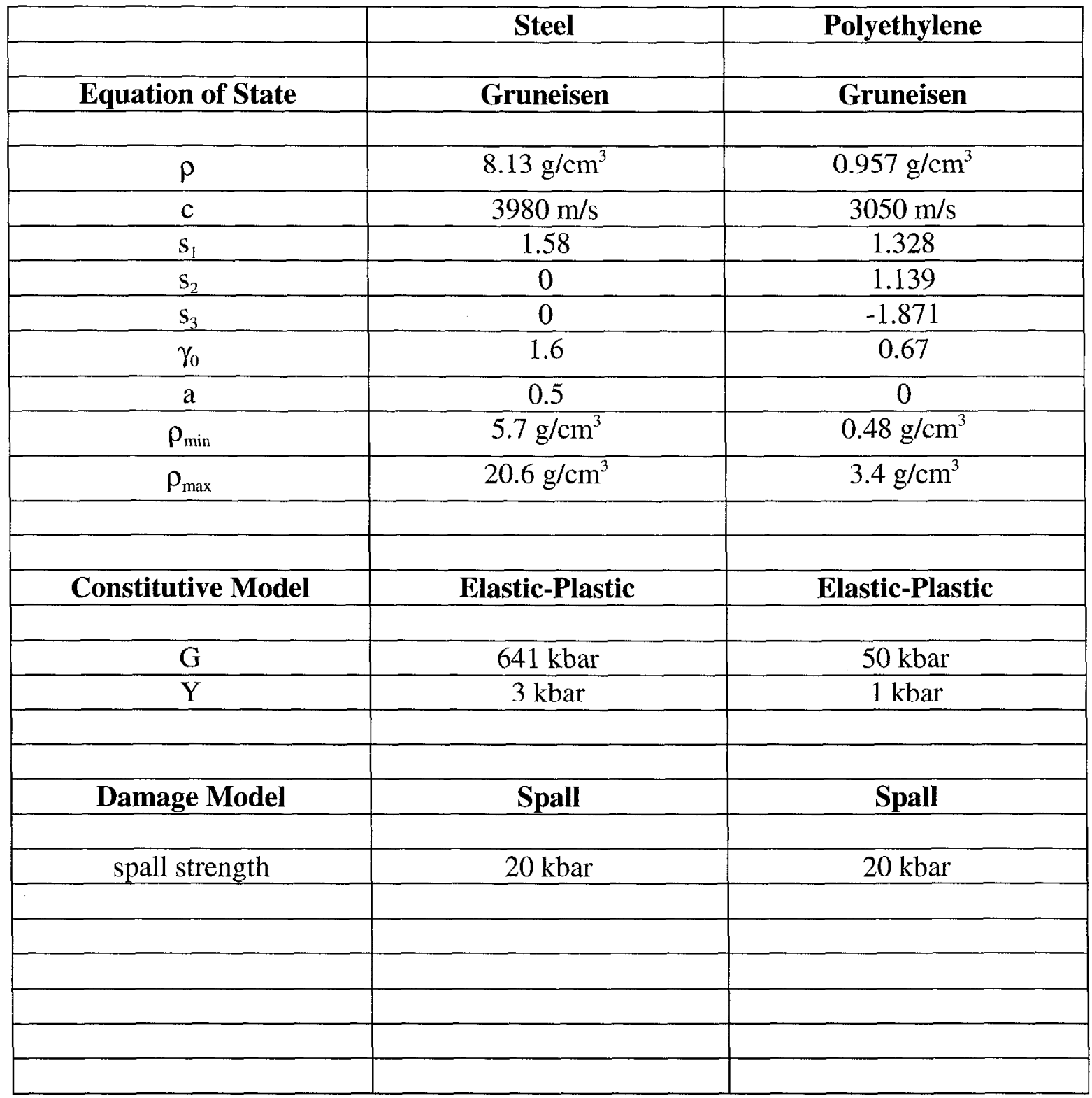


Table 2

Calculated penetration depths at,various incident velocities for steel projectile impinging normally on polyethylene

\begin{tabular}{|c|c|c|}
\hline Incident velocity & $\begin{array}{c}\text { LLNL Calculation } \\
\text { (this work) }\end{array}$ & $\begin{array}{c}\text { CEA Calculation } \\
\text { (ref. 2) }\end{array}$ \\
\hline $550 \mu m$ diameter projectile & & $0.3 \mathrm{~mm}$ \\
\hline $0.35 \mathrm{~km} / \mathrm{s}$ & $0.48 \mathrm{~mm}$ & $1.1 \mathrm{~mm}$ \\
\hline $0.85 \mathrm{~km} / \mathrm{s}$ & $1.50 \mathrm{~mm}$ & $1.7 \mathrm{~mm}$ \\
\hline $1.10 \mathrm{~km} / \mathrm{s}$ & $2.08 \mathrm{~mm}$ & \\
\hline & & \\
\hline & & \\
\hline & & $1.3 \mathrm{~mm}$ \\
\hline
\end{tabular}


Table 3

Material parameters for the second calculations. Results are presented in figs 7-11.






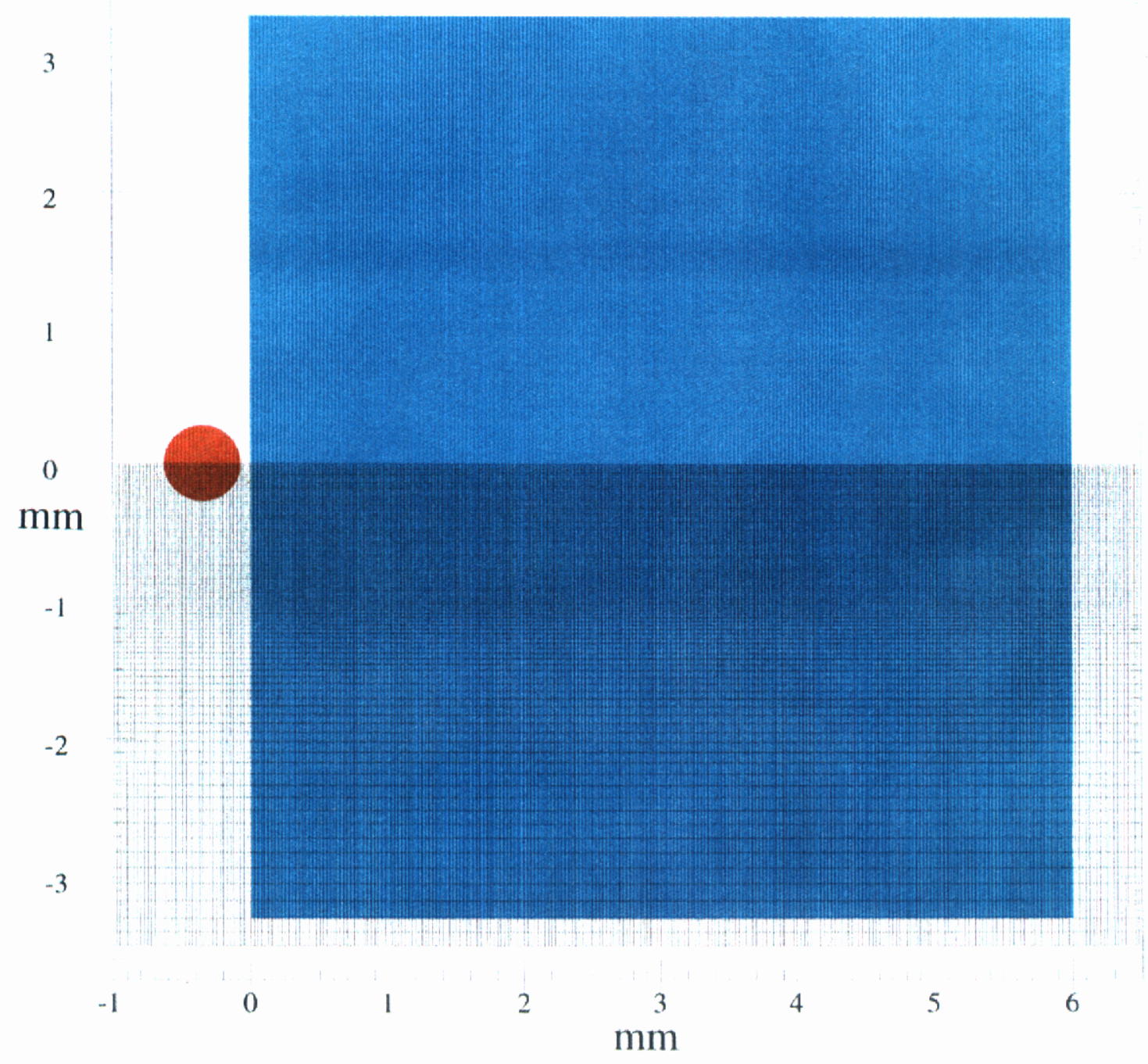

Figure 1: Initial problem setup showing zoning. 


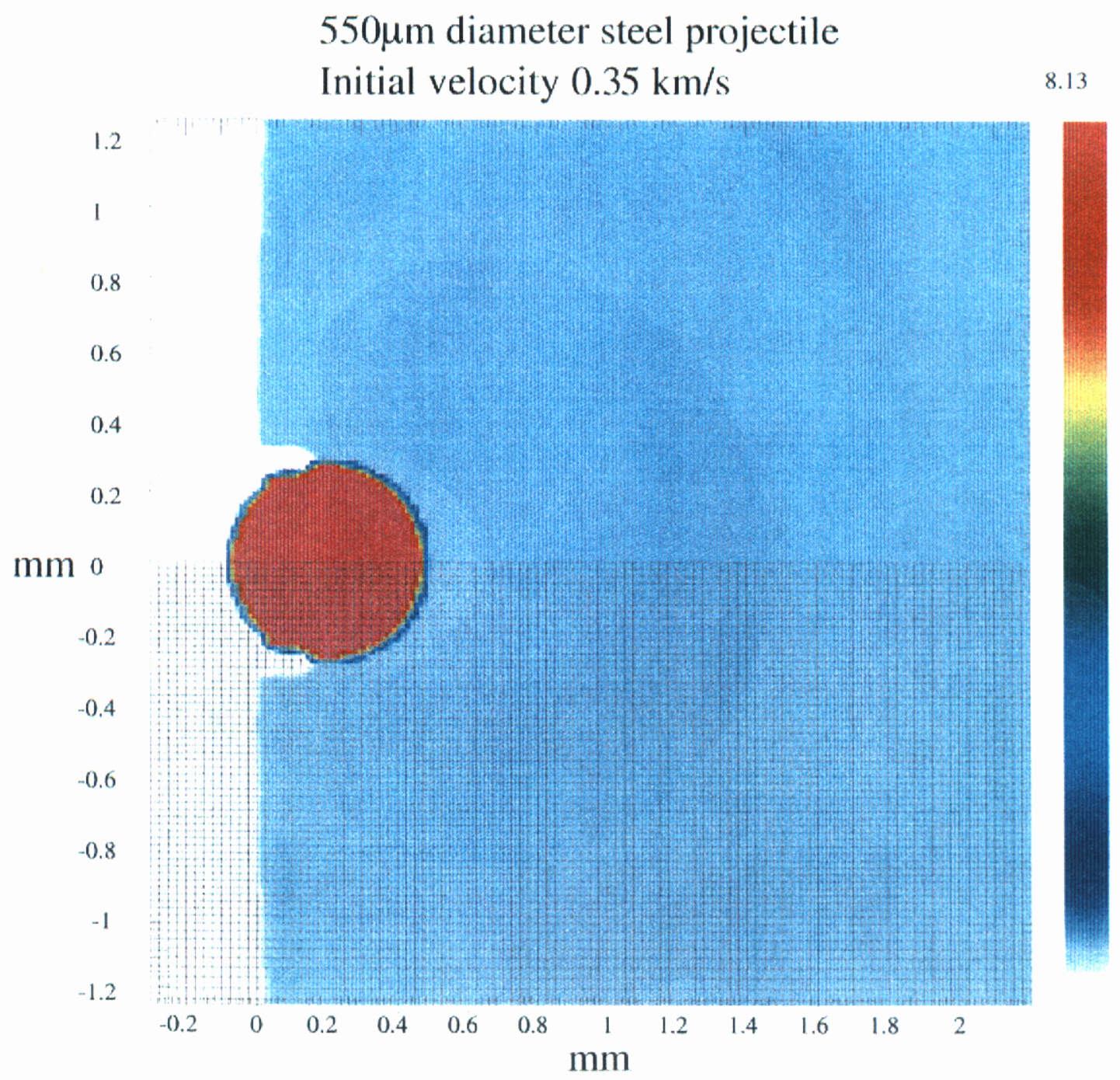

Figure 2: Cross section through the calculation showing material densities At $10 \mu \mathrm{sec}$, after the projectile has stopped. The incident projectile's Diameter and speed are shown at the top of the figure. Material models And parameters are made as close as possible to those used in Reference 2. These material parameters are presented in Table 1. 


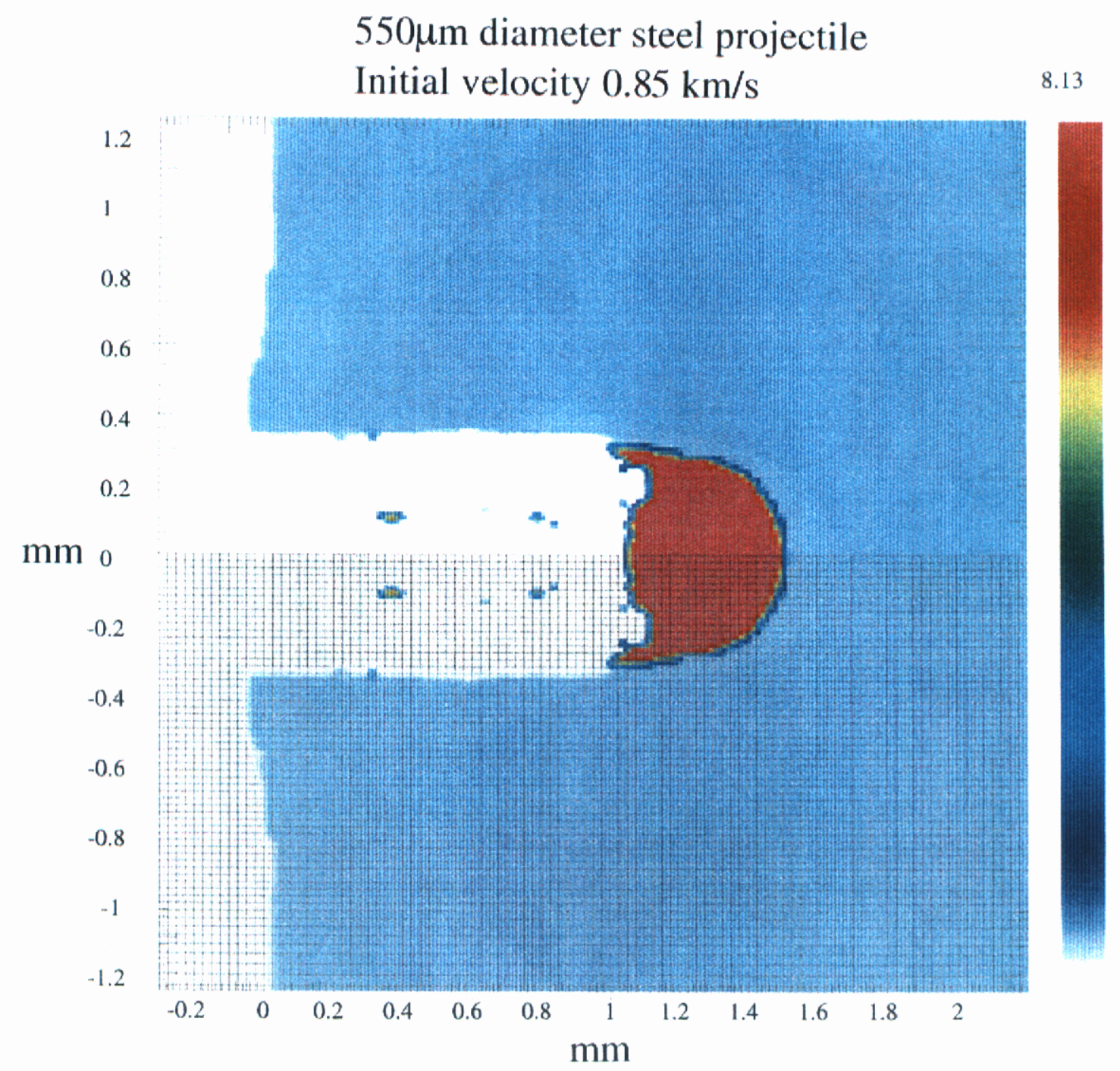

Figure 3: Cross section through the calculation showing material densities at 10 usec, after the projectile has stopped. The incident projectile's diameter and speed are shown at the top of the figure. Material models and parameters are made as close as possible to those used in Reference 2. These material parameters are presented in Table 1. 


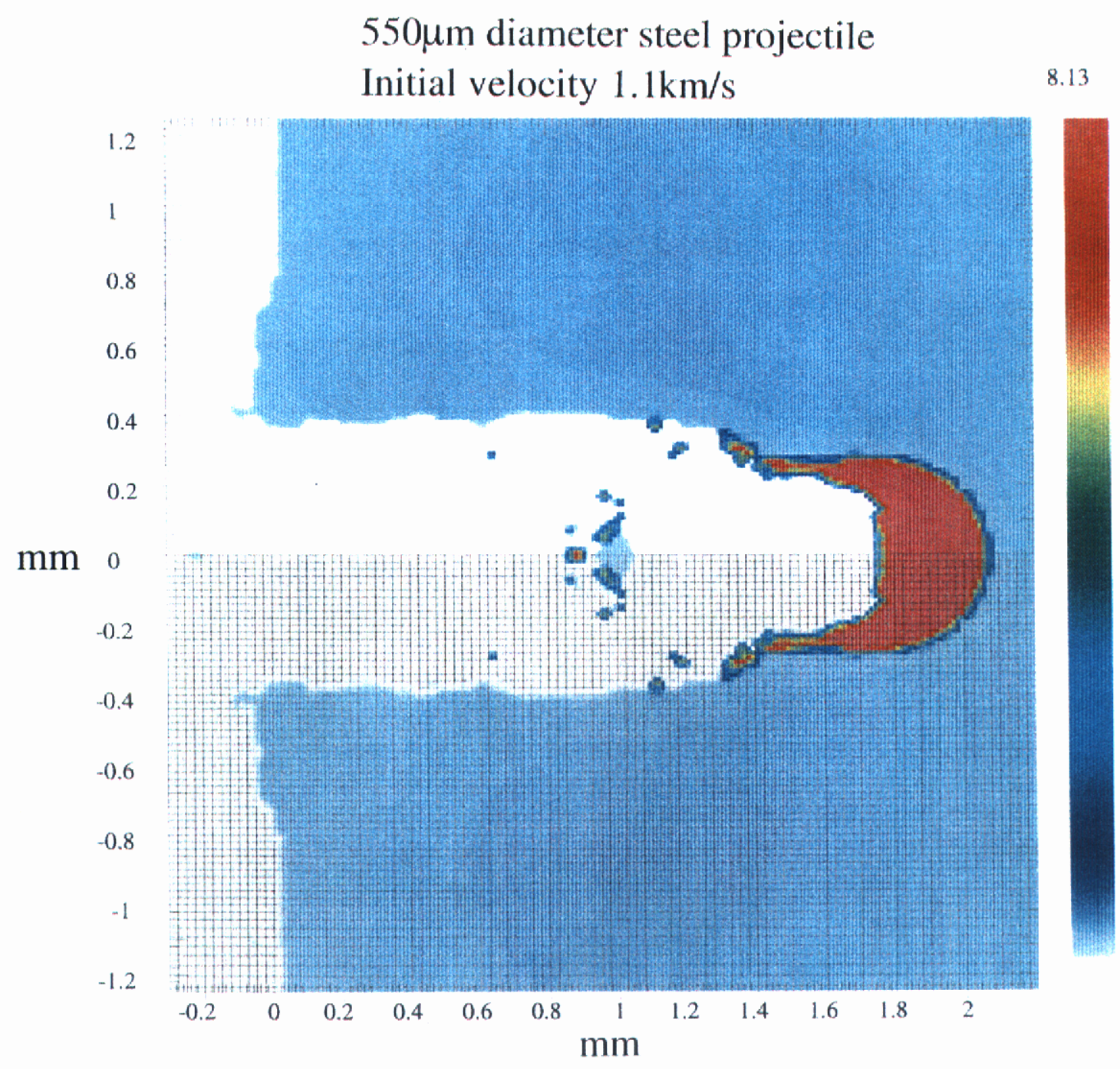

Figure 4: Cross section through the calculation showing material densities at $10 \mu \mathrm{sec}$, after the projectile has stopped. The incident projectile's diameter and speed are shown at the top of the figure. Material models and parameters are made as close as possible to those used in Reference 2. These material parameters are presented in Table 1. 


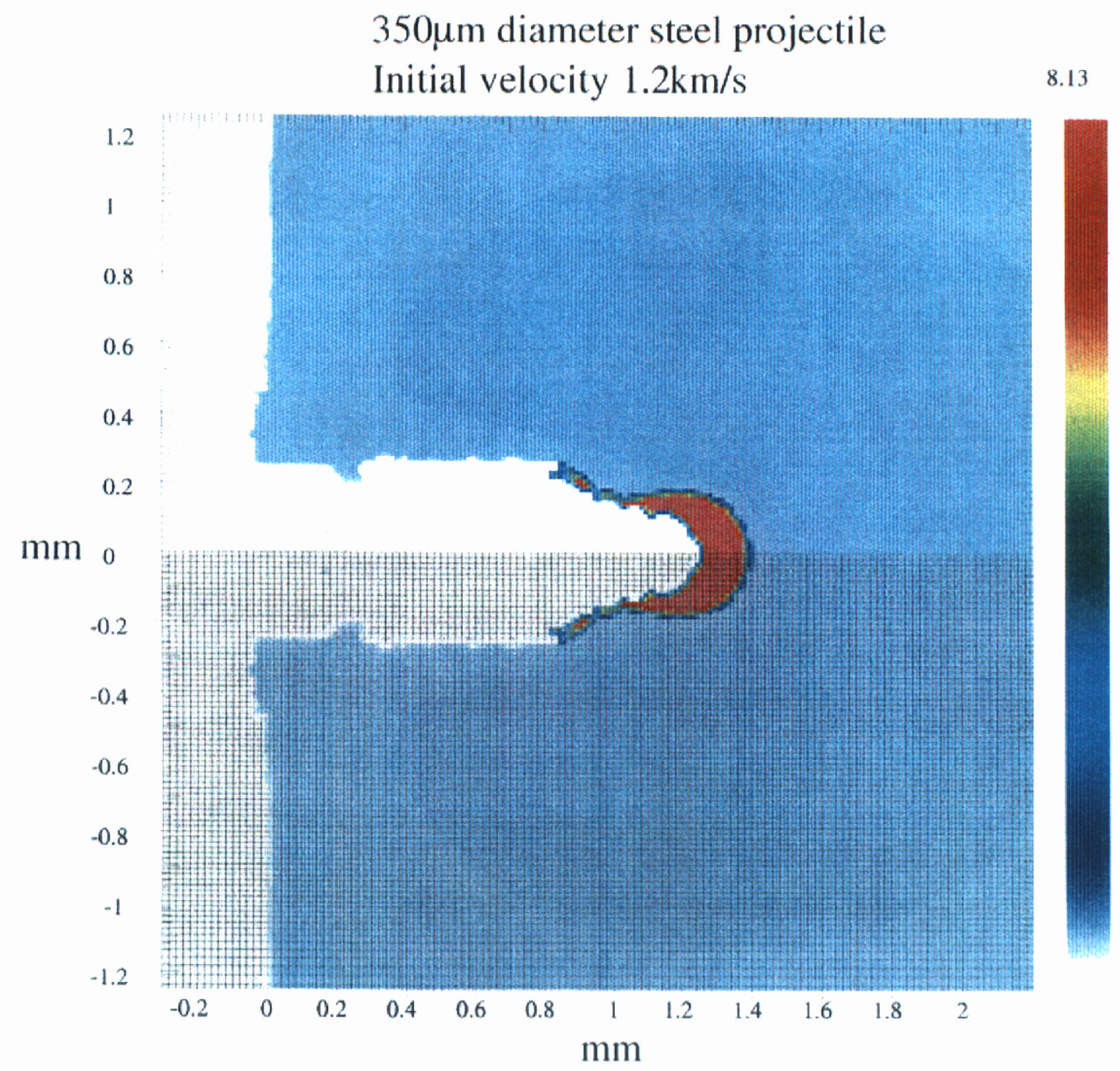

Figure 5: Cross section through the calculation showing material densities at $10 \mu \mathrm{sec}$, after the projectile has stopped. The incident projectile's diameter and speed are shown at the top of the figure. Material models and parameters are made as close as possible to those used in Reference 2. These material parameters are presented in Table 1. 


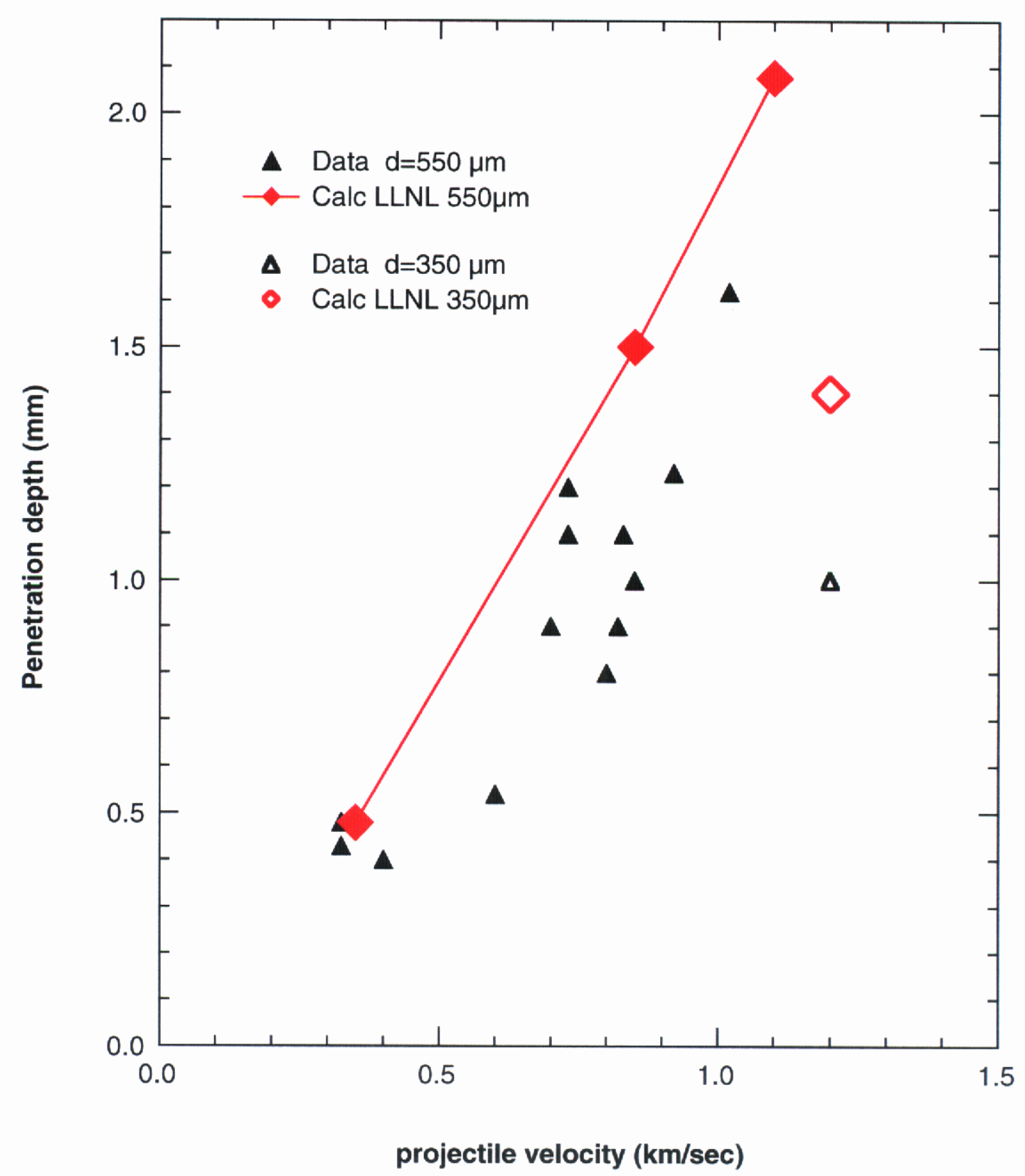

Figure 6: Penetration depth into polyethylene vs. initial velocity of the stainless steel projectile. The material properties are presented in table 1; these were chosen to be as close as possible to those used by Geille of the CEA (ref. 2). Solid and open symbols are used for $550-\mu \mathrm{m}$ and $350-\mu \mathrm{m}$ information, respectively. 




Figure 7: Cross section through the calculation showing material densities at $10 \mu \mathrm{sec}$, after the projectile has stopped. The incident projectile's diameter and speed are shown at the top of the figure. Some modified material models and parameters are taken from LLNL sources. These material parameters are presented in Table 3. 


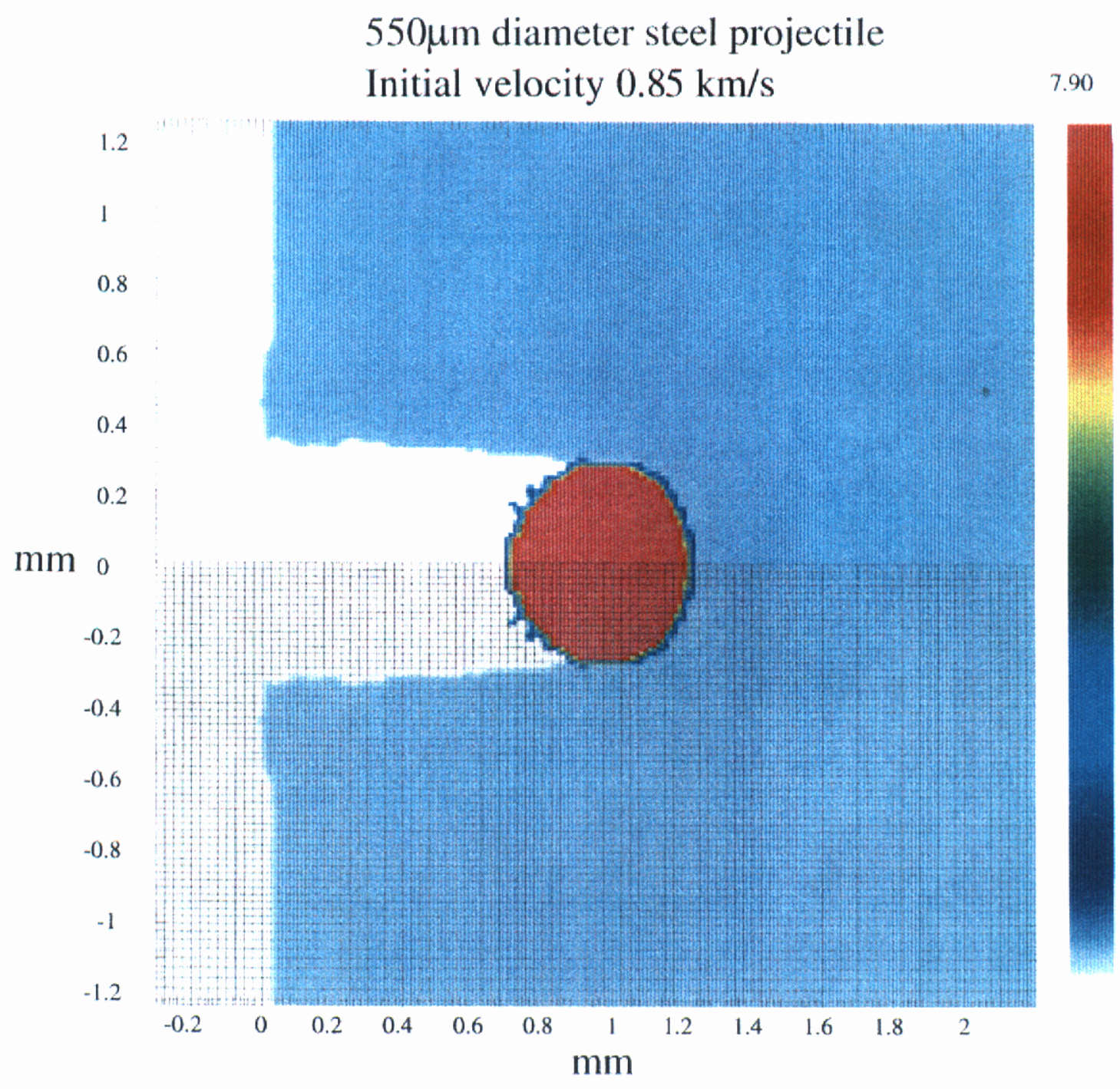

Figure 8: Cross section through the calculation showing material densities at $10 \mu \mathrm{sec}$, after the projectile has stopped. The incident projectile's diameter and speed are shown at the top of the figure. Some modified material models and parameters were taken from LLNL sources. These material parameters are presented in Table 3. 




Figure 9: Cross section through the calculation showing material densities at $10 \mu \mathrm{sec}$, after the projectile has stopped. The incident projectile's diameter and speed are shown at the top of the figure. Some modified material models and parameters were taken from LLNL sources. These material parameters are presented in Table 3. 


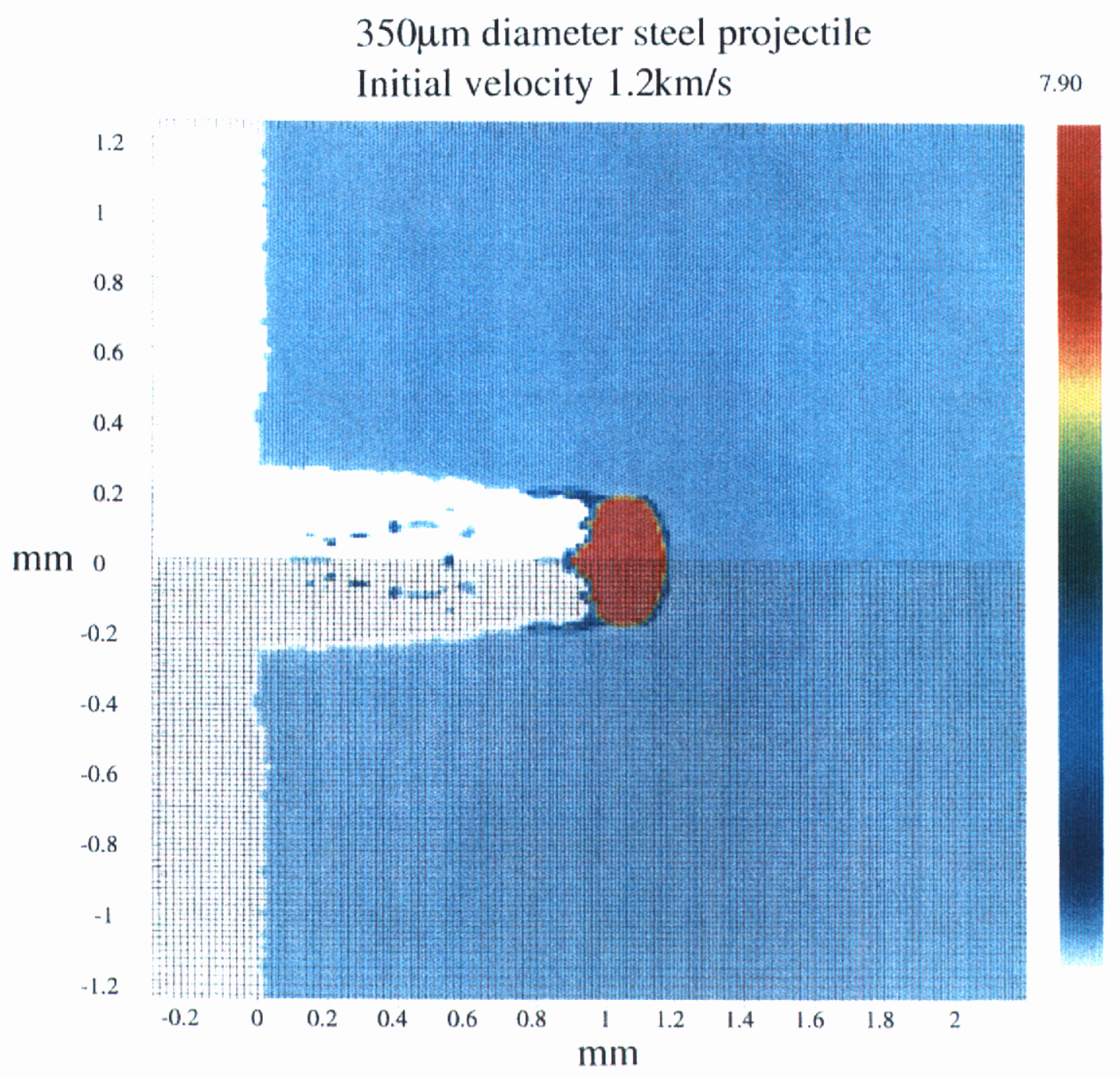

Figure 10 section through the calculation showing material densities at $10 \mu \mathrm{sec}$, after the projectile has stopped. The incident projectile's diameter and speed are shown at the top of the figure. Some modified material models and parameters were taken from LLNL sources. These material parameters are presented in Table 3. 


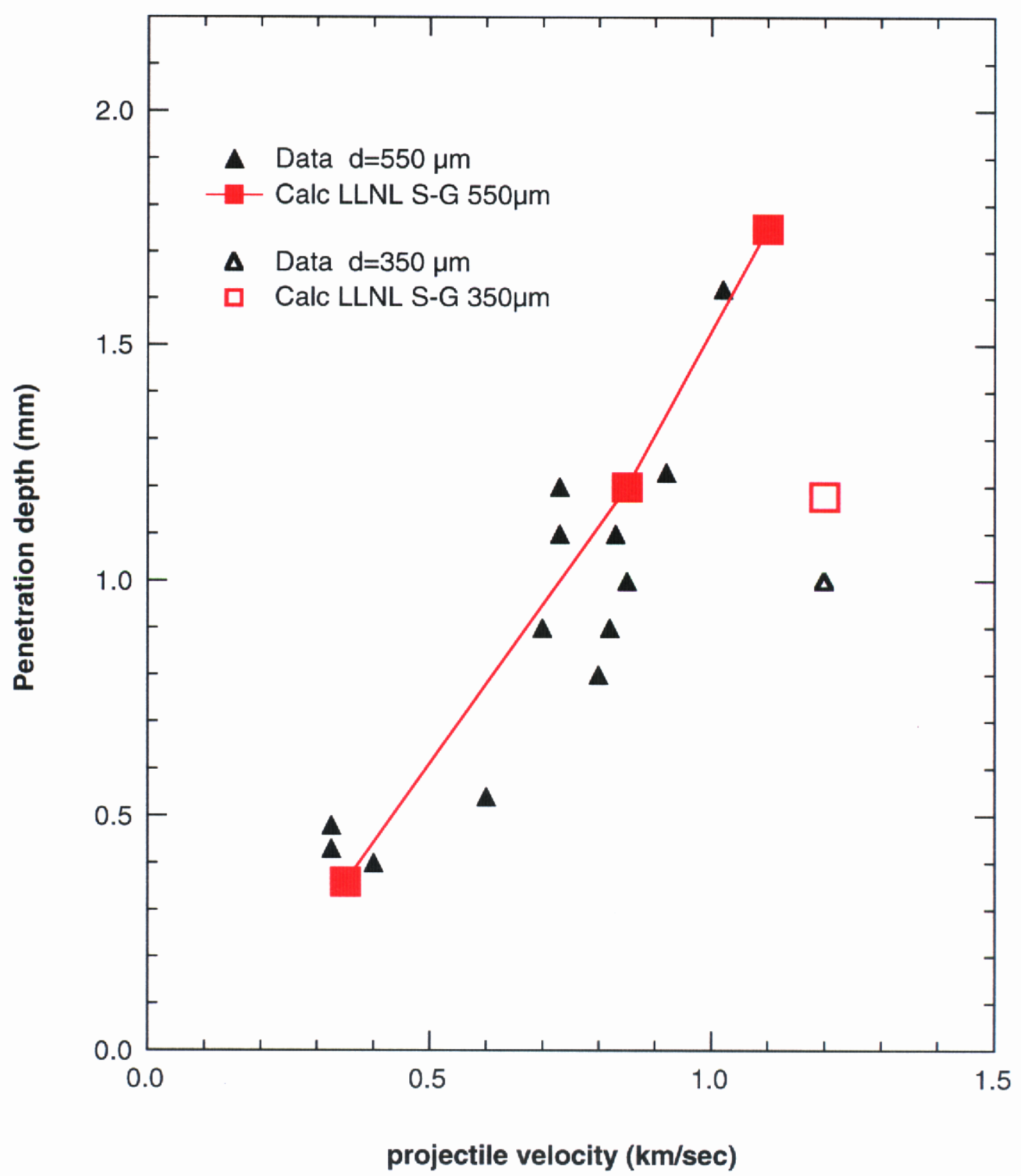

Figure 11: Penetration depth into polyethylene vs. initial velocity of the stainless steel projectile. The material properties are presented in table 3; these use the SteinbergGuinan constitutive model for stainless steel (ref. 5). These material properties are the best available for this problem. Solid and open symbols are used for $550-\mu \mathrm{m}$ and 350$\mu \mathrm{m}$ information, respectively. 